\title{
Fotovoltaik Uygulamalar için Empedans Kaynaklı bir Mikroinverterin Matlab/Simulink yardımıyla Analizi
}

\author{
${ }^{1 *}$ Mustafa Sacid Endiz, ${ }^{2}$ Ramazan Akkaya \\ 1*Elektrik ve Elektronik Mühendisliği Bölümü, Mühendislik ve Mimarlık Fakültesi, Necmettin Erbakan Üniversitesi, \\ Konya, Türkiye \\ ${ }^{2}$ Elektrik-Elektronik Mühendisliği Bölümü, Mühendislik Fakültesi, Selçuk Üniversitesi, Konya, Türkiye
}

\section{Özet}

Empedans kaynaklı mikroinverter, geleneksel gerilim kaynaklı inverterlerin kavramsal ve teorik sınırlamalarını ortadan kaldırır ve yeni bir güç dönüştürme konsepti sağlar. Bu çalışmada, son zamanlarda giderek yaygınlaşan ve fotovoltaik sistemlerde kullanılan empedans kaynaklı bir mikroinverter devresinin bilgisayar ortamında Matlab/Simulink yardımıyla analizi yapılmıştır. Klasik inverterler ile arasında genel bir karşılaştırma yapıldıktan sonra farklı topolojilerin avantajları ve dezavantajlarına değinilmiştir. Empedans kaynaklı mikroinverter devrelerinin çalışma prensibi, kontrol yöntemi ve temel özellikleri açıklanmıştır. Empedans kaynaklı mikroinverter yapısının Matlab/Simulink ortamında benzetimi gerçekleştirilmiştir.

Anahtar kelimeler: Fotovoltaik, mikroinverter, empedans kaynaklı inverter

\section{Analysis of Z-Source Microinverter for Photovoltaic Applications using Matlab/Simulink Environment}

\author{
Mustafa Sacid Endiz1, Ramazan Akkaya² \\ ${ }^{1 *}$ Faculty of Engineering and Architecture, Department of Electrical and Electronics Engineering, Necmettin \\ Erbakan University, Konya, Turkey \\ ${ }^{2}$ Faculty of Faculty of Engineering and Natural Sciences, Department of Electrical and Electronics Engineering, \\ Konya Technical University, Konya, Turkey
}

\begin{abstract}
Z-source microinverter circuit overcomes the conceptual and theoretical limitations of traditional voltage source inverters and provides a new power conversion concept. This paper presents Z-source microinverter system which has become increasingly popular in recent times for photovoltaic applications using Matlab/Simulink environment. After a general comparison with conventional inverters, the advantages and disadvantages of different topologies are discussed. The operating principle, control method and basic characteristics of Z-source microinverter circuits are explained. Matlab/Simulink simulations are shown to verify the proposed circuit along with the results.
\end{abstract}

Keywords: Photovoltaic, microinverter, Z-source inverter circuit

*Corresponding author: Address: Faculty of Engineering and Architecture, Department of Electrical and Electronics Engineering, Necmettin Erbakan University, 42140, Konya TURKEY. E-mail address: msendiz@konya.edu.tr, Phone: +903323252024 


\section{Giriş}

Son yıllarda dünya genelindeki artan nüfus ve küresel 1sınma neticesinde şekillenen enerji politikaları enerjiye olan talebi belirgin ölçüde arttırmıştır. Elektrik enerjisi üretimi için mevcut enerji kaynaklarının kullanımı dünya genelinde giderek artarken bu kaynakların rezervleri de buna bağlı olarak azalmaktadır. Bu kaynakların tüketimi; enerji krizine, küresel 1sınmaya ve atmosfere karbon salımı gibi büyük çevresel sorunlara yol açmaktadır. Bu nedenle sürdürülebilir, tükenmez ve çevre dostu olan yenilenebilir enerji kaynaklarına olan ilgi her geçen gün artmaktadır [1-2]. Yenilenebilir enerji kaynaklarının başında güneş enerjisi gelmektedir. Güneşten gelen foton enerjisi fotovoltaik (PV) paneller yardımıyla doğru akım (DC) elektrik enerjisine dönüştürülür. $\mathrm{Bu}$ enerjinin evlerde kullanılabilmesi için alternatif akıma (AC) dönüştürülmesi gerekmektedir. Bu dönüşüm inverterlerle yapılmaktadır [3]. İnverterler Şekil 1'de görüldüğü gibi merkezi, dizi, çoklu-dizi ve panele bütünleşik olarak tasarlanan mikroinverter olmak üzere 4 kısma ayrılır.

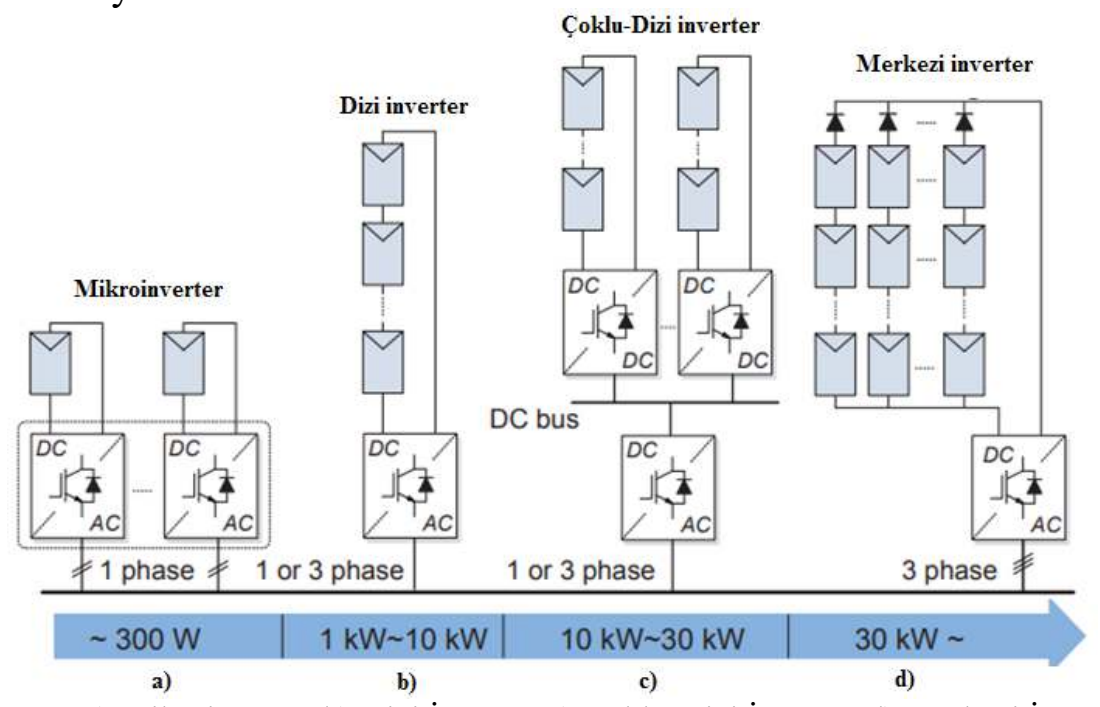

Şekil 1. a) Mikroinverter b) Dizi İnverter c) Çoklu-Dizi İnverter d) Merkezi İnverter

\section{Materyal ve Metot}

\subsection{Empedans Kaynaklı Mikroinverterler}

Mikroinverterler, isminden de anlaş1lacağı gibi düşük güç seviyelerinde (100W-300W) güneş panellerine tümleşik olacak şekilde monte edilen ve panelden direkt olarak AC güç almamızı sağlayan güç dönüştürücüleridir. Büyük güçlü olan merkezi ve dizi inverterlerde yüksek giriş gerilimine ihtiyaç duyulur, bunun sonucunda birden fazla güneş panelinin seri bağlanması gerekmektedir. Panellerde meydana gelebilecek muhtemel bir arıza, gölgelenme veya kirlenme birbirine seri bağlı olan tüm panellerdeki akım akışını kısmen de olsa etkileyecektir. Bu gibi problemler bütün bir sistemi kullanılamaz hale getirmekte ve verimin oldukça düşmesine neden olabilmektedir. Mikroinverterlerde ise herhangi bir panelde meydana gelebilecek olumsuz bir durum sadece ilgili panelin verimliliğine olumsuz etki edecek ve genel sistem üzerinde çok daha az etki meydana getirecektir [4]. 
Çok çeşitli alanlarda kullanılan klasik inverterler, gerilim kaynaklı ya da akım kaynaklı olarak seçilmektedir. Her iki yapının da kendine has dezavantajları vardır. Klasik inverterlerin dezavantajları genel olarak şu şekilde sıralanabilir:

1) DC gerilim seviyesinin yetersiz olması durumunda DC-DC dönüştürücü kullanılarak geriliminin yükseltilmesi gerekmektedir.

2) İnverterin aynı kolunda yer alan alt ve üst sıra anahtarlar, aynı anda iletime sokulamaz. Elektromanyetik girişim (EMI) gibi istenmeyen durumlarda anahtarlar bu konuma gelebilir ve sistem için risk oluşturur.

3) Anahtarların iletime girme anları arasında bırakılan ölü zaman, çıkış geriliminde harmoniklere sebep olur.

PV panellerin çıkış gerilimleri çevre şartlarına bağlı olarak geniş bir aralıkta değişsebilmektedir. Bundan dolayı endüstriyel uygulamalarda kullanılan mikroinverterler, beraberinde DC-DC dönüştürücü kullanımını zorunlu kılmaktadır. $\mathrm{Bu}$; maliyet, verim ve hacim açısından olumsuz bir etki olarak karşımıza çıkmaktadır. Mikroinverterlerin girişine uygulanan DC gerilim seviyesi değişken ve düşük seviyeli olduğundan genellikle yükselten dönüştürücü yapılarından birisi tercih edilir. PV sistemlerin en önemli bileşenlerinden biri olan gerilim ve akım kaynaklı inverterlerin dezavantajlarını ortadan kaldırabilmek için, son yıllarda DC-DC dönüştürücüye ihtiyaç duymaksızın gerilimi düşürebilen ve yükseltebilen empedans kaynaklı inverterler ortaya konmuştur [5]. Bu nedenle empedans kaynaklı inverter, fotovoltaik sistemler için önemli bir alternatif yapı olarak kendini göstermiştir. Şekil 2 ve Şekil 3 'te sırasıyla gerilim kaynaklı inverter yapısı ile empedans kaynaklı bir inverter yapısı görülmektedir.
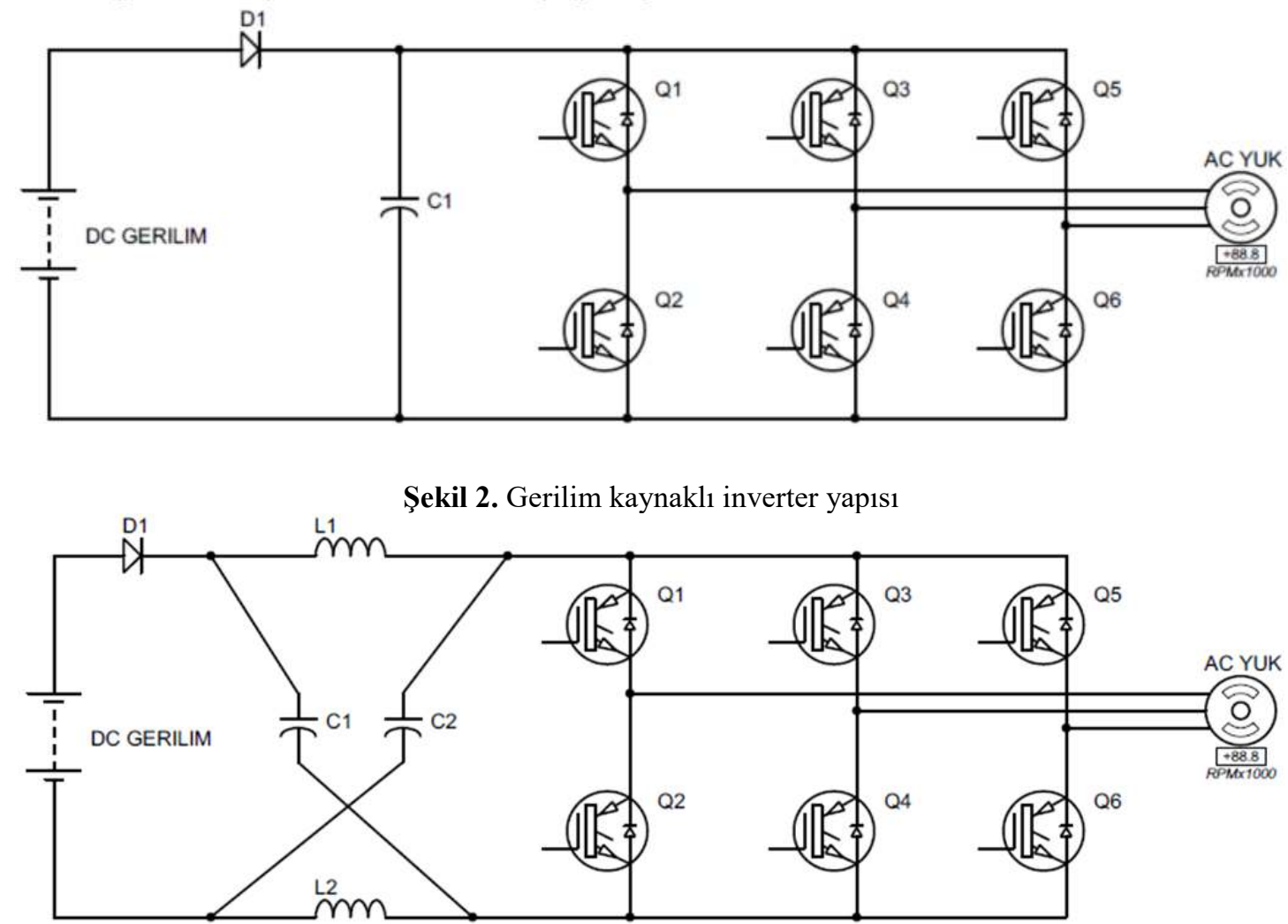

Şekil 3. Empedans kaynaklı inverter yapısı 
Empedans kaynaklı inverter, düşürücü-yükseltici olarak çalışabilmekte ve bu nedenle geniş bir gerilim aralığında çalışmayı gerektiren güç elektroniği uygulamalarında DC-DC dönüştürücü ihtiyacını ortadan kaldırmaktadır. Bunun sonucunda sistemde daha az yarıiletken anahtar kullanılarak, sistemin toplam hacmi ve maliyeti aşağıya çekilmiştir. Ayrıca empedans kaynaklı inverterlerde DC kaynağın inverter kolları üzerinden kısa devre ya da açık devre olmasının sistem için bir risk teşkil etmemesi nedeniyle güvenilir bir devredir [4-6].

Empedans kaynaklı inverterlerde, genel yaklaşımın aksine girişteki DC bara gerilimi yükseltmek için inverter kollarının kısa devre edilerek çalıştırılması esastır. Her bir anahtarlama periyodu içerisinde kısa devre çalışmaya belirli bir süre ayrılır ve bu süre gerilim yükseltme oranını belirler.

Empedans kaynaklı inverterde Darbe Genişlik Modülasyon (DGM) kontrol yöntemleri üç ayrı başlık altında incelenebilir. Bunlar sırasıyla; basit yükseltici kontrol (BYK), maksimum yükseltici kontrol (MYK) ve maksimum sabit yükseltici kontrol (MSYK) [7-10]. Şekil 4 ve 5 'te sırasıyla empedans kaynaklı inverter için maksimum güç noktası takip (MPPT) blok yapısı ve maksimum güçteki V-I ve P-V karakteristik eğrileri görülmektedir.

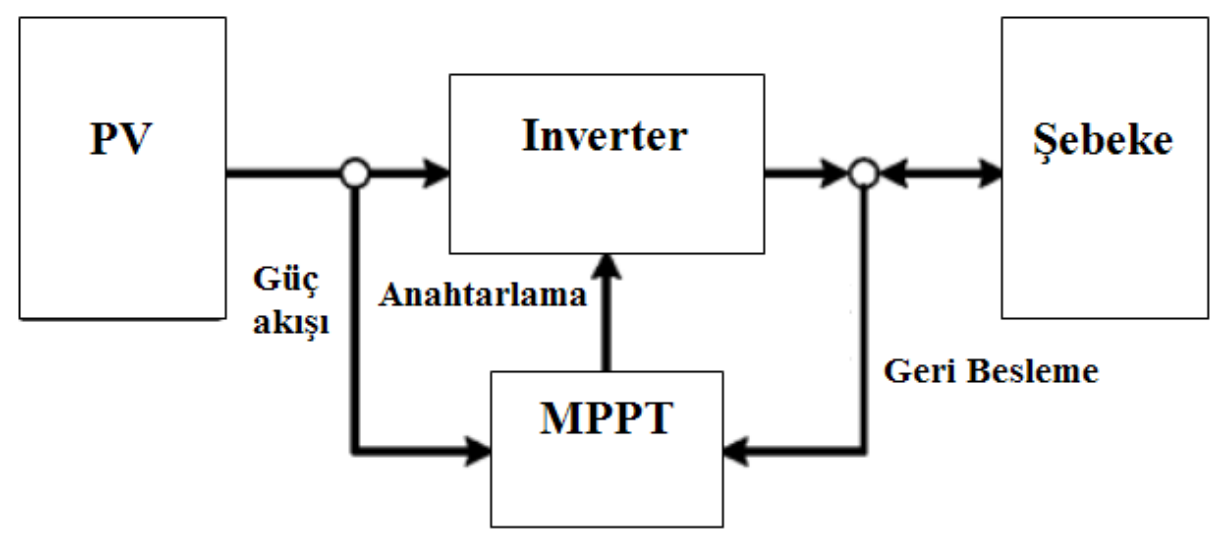

Şekil 4. Empedans kaynaklı inverter için MPPT blok yapısı

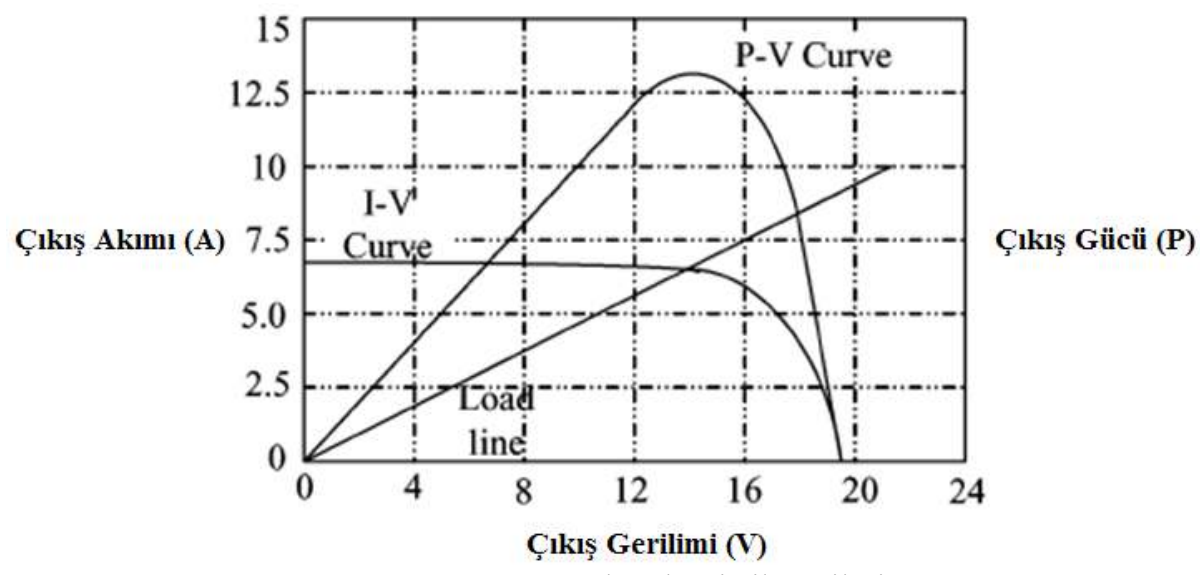

Şekil 5. V-I ve P-V karakteristik eğrileri

$\mathrm{Bu}$ çalışmada empedans kaynaklı inverterin Matlab/Simulink ortamında benzetimi gerçekleştirilmiştir. Matlab/Simulink ortamında çalışmak araştırmacılara tasarım esnasında esneklik ve pek çok durumda değişen parametre değerlerinin kolaylıkla uygulanmasına imkân 
sağlar, çalışmaya güvenirlilik kazandırır. Bu yönleri ile Matlab platformu hem zamandan hem de hatalı veya tahmini değerlerle siparişleri verilebilecek malzeme ve komponentlerden tasarruf etmeye imkân tanır.

\section{Empedans Kaynaklı Mikroinverter Matlab/Simulink Analizi}

Uygulamada çok yaygın olarak kullanılan iki inverter sistemi Şekil 6'da görülmektedir. Şekil 6(a)'da, inverterden sonra gerilimi yükseltmek için hat frekansındaki bir trafo kullanılır. Genel olarak, bir hat frekans transformatörünün büyük boyutu, yüksek gürültüsü ve maliyeti vardır. Dahası, inverter girişindeki geniş gerilim değişikliği ile başa çıkmak için inverterin gücünün büyük boyutlarda olması gerekir. Böylece trafoyu ortadan kaldırmak ve inverterin gerekli kVA değerini düşük tutmak için, birçok uygulamada, Şekil 6(b)'de gösterildiği gibi yüksek frekanslı bir DC-DC dönüştürücü kullanılır. DC-DC dönüştürücüdeki anahtarların maliyetli oluşu, anahtarlama kayıpları ve sistemin verimliliğine olumsuz etkisinden dolayı yeni topoloji çalışmaları yapılmaktadır.

Empedans kaynaklı inverter, Şekil 3'te gösterildiği gibi, pasif bileşenleri kullanarak giriş gerilimini yükseltebilen alternatif bir güç dönüştürme topolojisidir. Dönüştürücü ana devresini güç kaynağına bağlamak için bölünmüş indüktör ve $X$ şeklinde bağlanmış kapasitöre sahip bir LC empedans ağını kullanır, bu da giriş gerilimini tek bir aşamada artırmanın yolunu sağlar. Empedans kaynağı ile gerilim yükseltilmesi tüm anahtarlama durumlarında gerçekleşebilir. Böylece sistem daha güvenilir ve sağlam hale gelir. Ayrıca empedans kaynağındaki indüktörler ve kapasitörler hem enerji depolama cihazlarıdır hem de küçük boyut ve düşük maliyet sağlamak için optimize edilmiş tasarım sağlarlar.

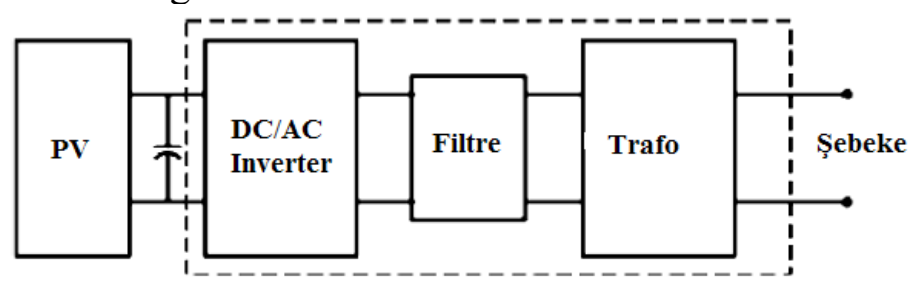

(a)

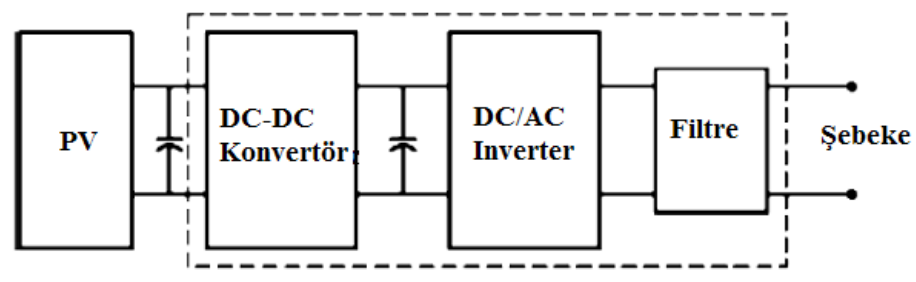

(b)

Şekil 6. a) Geleneksel trafolu inverter yapısı b) DC-DC dönüştürücülü mikroinverter yapısı

Şekil 6'daki topolojiler ile karşılaştırıldığında, Şekil 3'deki sistemde, devredeki gerilimi yükseltmek için ne büyük bir trafoya ne de bir DC-DC dönüştürücüye ihtiyaç vardır. Boyut ve maliyet en aza indirilmiştir. Ölü zaman gerekmediğinden, kontrol yapısı ve toplam harmonik distorsiyon (THD) değeri geliştirilebilir. Doğrudan inverter sistemleri ile karşılaştırıldığında empedans kaynaklı inverterler, minimum kVA gereksinimine sahiptir. Yüzde 50 aralığındaki bir gerilim değişimine sahip inverter sisteminde, 10kW'lık bir PV sistemi, gerilim değişiminin 
üstesinden gelebilmek için 20kW'lı bir invertere ihtiyaç duyar. Empedans kaynaklı inverter yapısının avantajından dolayı, 10kW'lık bir PV sistemi için 10kW gücünde inverter kullanmak yeterli olacaktır. Bu nedenle, empedans kaynaklı inverterler kullanılarak hacim, maliyet ve aynı zamanda aktif anahtarlama cihazlarının sayısı en aza indirgenir.

Empedans kaynaklı inverter topolojisinde çıkış gerilimi inverter faz kollarında gerçekleştirilen kısa devre çalışma ile yükseltilebilmektedir. Bu çalışma şekli gerçekte geleneksel inverter yapılarında asla gerçekleştirilmemesi gereken bir durumdur. Bu yönüyle empedans kaynaklı inverter, tek katlı güç çevrim yapısına sahip, daha az karmaşık ve düşük maliyetli bir devre yapısı olarak görülmelidir. Bunlara ek olarak, kısa devre çalışmanın da inverter yapısına zarar vermediği göz önüne alındığında daha güvenilir bir çalışma söz konusudur. Geleneksel inverterlerde, DC giriş gerilimi yük ile değişmektedir. Empedans kaynaklı inverterde ise, kısa devre çalışma durumunun kontrol edilmesi ile anahtarlama elemanlarının gerilim kapasitelerini zorlamamak kaydı ile istenilen çıkış gerilimi sağlanmaktadır.

Sonuç olarak empedans kaynaklı inverterde;

1) İnverterde gerilim yükseltme ve maksimum gücü elde etmek için sadece bir kademe olacaktır.

2) Anahtarlama cihazlarının sayısı azaltılacak ve daha az kayıp olacaktır.

3) Ölü zamana ihtiyaç duyulmayacağından THD değeri istenen değerlerde olacaktır.

4) İnverter çalışması durumunda aynı fazdaki anahtarlar eş zamanlı olarak iletime geçebilecektir.

Şekil 7'de Matlab/Simulink ortamında geliştirilmiş olan empedans kaynaklı inverter modeli verilmiştir.

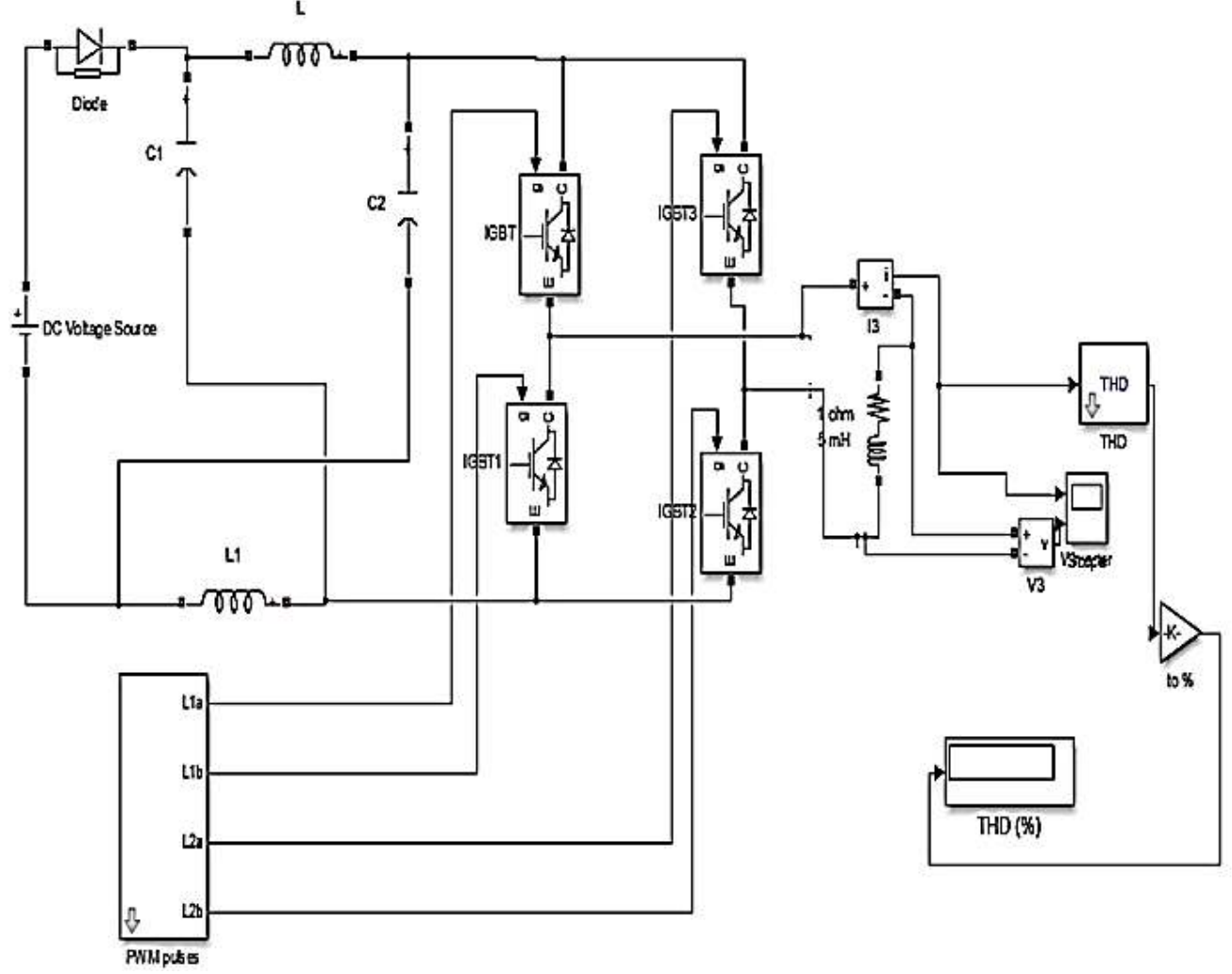

Şekil 7. Matlab/Simulink Empedans kaynaklı inverter modeli 
Empedans ağındaki L1 ve L2 indüktörleri ile C1 ve C2 kapasitörlerinin aynı indüktans ve kapasitans değerlerine sahip olduklarını varsayarsak, simetrik Z-kaynak ağı oluşmuş olur.

Çıkış AC gerilimi ve giriş DC gerilimi arasındaki ilişki şu şekilde bulunur:

Vout $=\mathrm{M}^{*} \mathrm{~B} * \mathrm{Vo}_{\mathrm{o}} / 2$

Vout çıkış AC gerilimi, Vo panel çıkış DC gerilimi, B boost faktörü, M ise H-köprü inverterin modülasyon indeksidir.

Modülasyon indeksi ise şu şekilde bulunur:

$\mathrm{M}=$ Vpeak / Vtri

Empedans kaynaklı inverter, ' $\mathrm{M}$ ' değerine bağlı olarak hem arttırıcı hem de azaltıcı olarak kullanılabilir. M 0.5'ten büyükse, inverter arttırıcı, 0.5 'ten küçükse azaltıcı olarak davranır.

Şekil 8'de empedans kaynaklı inverter anahtarlama devresi, Şekil 9 ve 10'da ise empedans kaynaklı inverter DGM sinyalleri ile düşük harmoniğe sahip çıkış gerilimi gösterilmiştir.

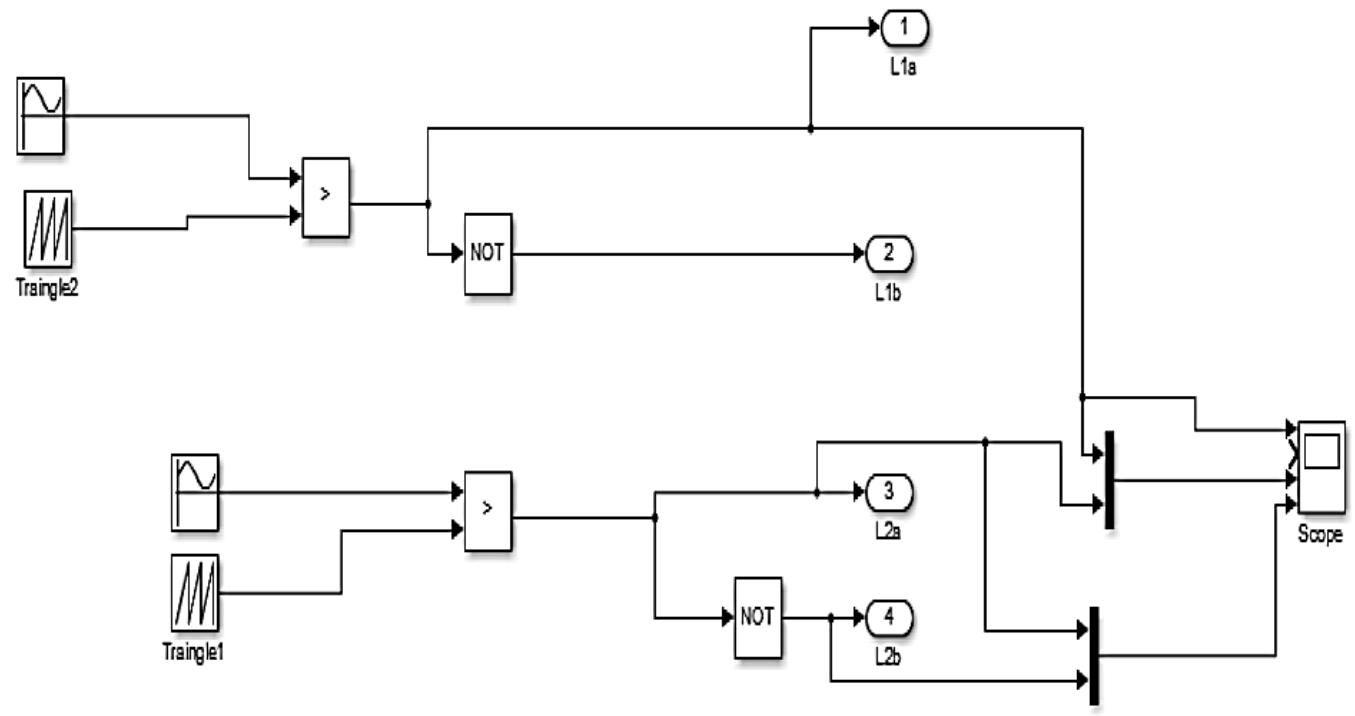

Şekil 8. Empedans kaynaklı inverter anahtarlama devresi
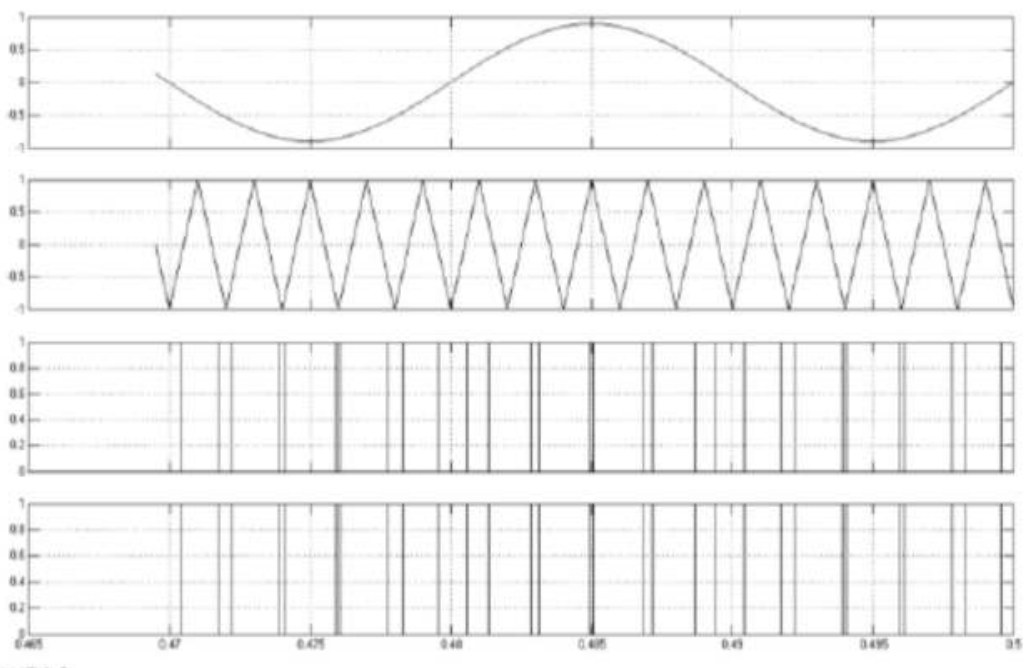

mitmen :

Şekil 9. Empedans kaynaklı inverter DGM sinyalleri 

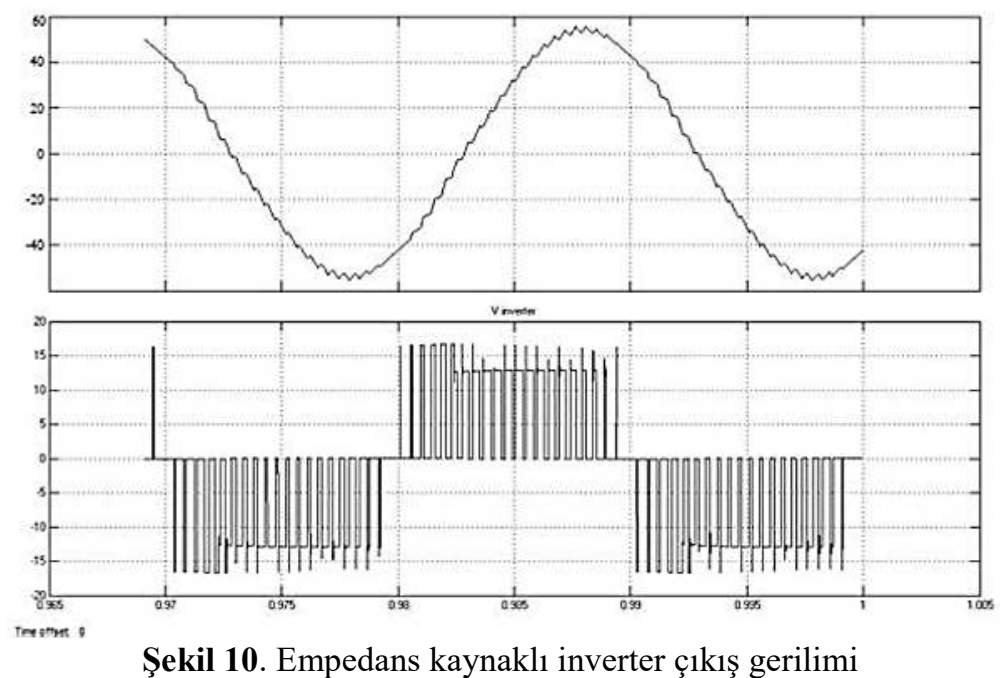

Şekil 10. Empedans kaynaklı inverter çıkış gerilimi

\section{Sonuç}

Son yıllarda gerilim ve akım kaynaklı inverterlerin dezavantajlarını ortadan kaldırmak amacıyla empedans kaynaklı inverter yapısı geliştirilmiştir. Bu yapı, düşürücü-yükseltici olarak çalışabilmekte ve bu sayede geniş bir gerilim aralığında çalışmayı gerektiren uygulamalarda DCDC dönüştürücü ihtiyacını ortadan kaldırmaktadır. Bu sayede sistemde daha az yarıiletken anahtar kullanılarak, sistemin toplam hacmi ve maliyeti en aza çekilmiştir. DC kaynağın inverter kolları üzerinden kısa devre ya da açık devre olmasının sistem için bir risk oluşturmaması nedeniyle güvenilir bir devredir. Bu çalışmada empedans kaynaklı mikroinverter devresinin temel özelliklerinden ve klasik inverter devre yapılarına göre farklılıklarından bahsedilmiştir. Devrenin Matlab/Simulink ortamında benzetimi gerçekleştirilmiş olup yapılan benzetimler sonucunda güneş paneli girişindeki DC akım, empedans kaynaklı mikroinverter sayesinde yüksek verim ve düşük harmonik içerikli olarak AC akıma dönüştürülmüştür.

Empedans kaynaklı inverter empedans ağında yapılabilecek tasarım değişikliklerine uygunluğundan, ileriki bilimsel çalışmalarda geliştirilmeye açık bir devre yapısı olarak karşımıza ç1kacaktır.

\section{Referanslar}

[1] S.B. Kjaer, J.H. Pedersen, F. Blaabjerg, "A Review of Single-Phase Grid-connected Inverters for Photovoltaic Modules", IEEE Trans. Industry Applica., vol. 41, no. 5, pp. 1292-1306, Sept. 2005.

[2] Shen, M., Joseph, A., Wang, J., Peng, F. Z., \& Adams, D. J. (2007). Comparison of traditional inverters and Z-source inverter for fuel cell vehicles. IEEE Transactions on Power Electronics, 22(4), 1453-1463.

[3] G. A. O'Sullivan, "Fuel cell inverters for utility applications", Proc. IEEE PESC'00, pp. 11911194, 2002. 
[4] K. H. Hussein, I. Muta, T. Hoshino, and M. sakada, "Maximum photovoltaic power tracking: An algorithm for rapidly changing atmospheric conditions," Proc. IEEE, vol. 142, no. 1, pp. 59-64, Jan. 1995.

[5] F. Z. Peng, “Z-source inverter," IEEE Trans. Ind. Appl., vol. 39, no. 2,pp. 504-510, Mar/Apr. 2003.

[6] M. Shen, A. Joseph, J. Wang, F. Z. Peng, and D. J. Adams, "Comparison of traditional inverters and Z-source inverter," in Proc. IEEE Power Electron. Spec. Conf., Jun. 2005, pp. 1692-1698.

[7] F. Z. Peng, A. Joseph, J. Wang, M. Shen, L. Chen, Z. Pan, E. Oritz-Rivera, Y. Huang, "Zsource inverter for motor drives", IEEE Trans. Power Electron., vol. 20, no. 4, pp. 857863, Jul. 2005.

[8] F. Z. Peng, X. M. Yuan, X. P. Fang, and Z.M. Qian, "Z-source inverter for adjustable speed drives," IEEE Power Electron Lett., vol. 1, no. 2, pp. 33-35, Jun. 2003.

[9] P. C. Loh, D. M. Vilathgamuwa, Y. S. Lai, G. T. Chua, and Y. W. Li,"Pulse-width modulation of Z-source inverters," in Conf. Rec. 39th IEEE IAS Annu. Meeting, Oct. 3-7, 2004, vol. 1, pp. 148-155.

[10] Y. Huang, M. Shen, F. Z. Peng, and J. Wang, -Z-source inverter for residential photovoltaic systems, || IEEE Trans. Power Electron., vol. 21,no. 6, pp. 1776-1782, Nov. 2006. 